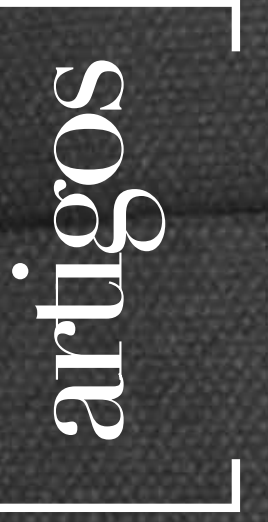




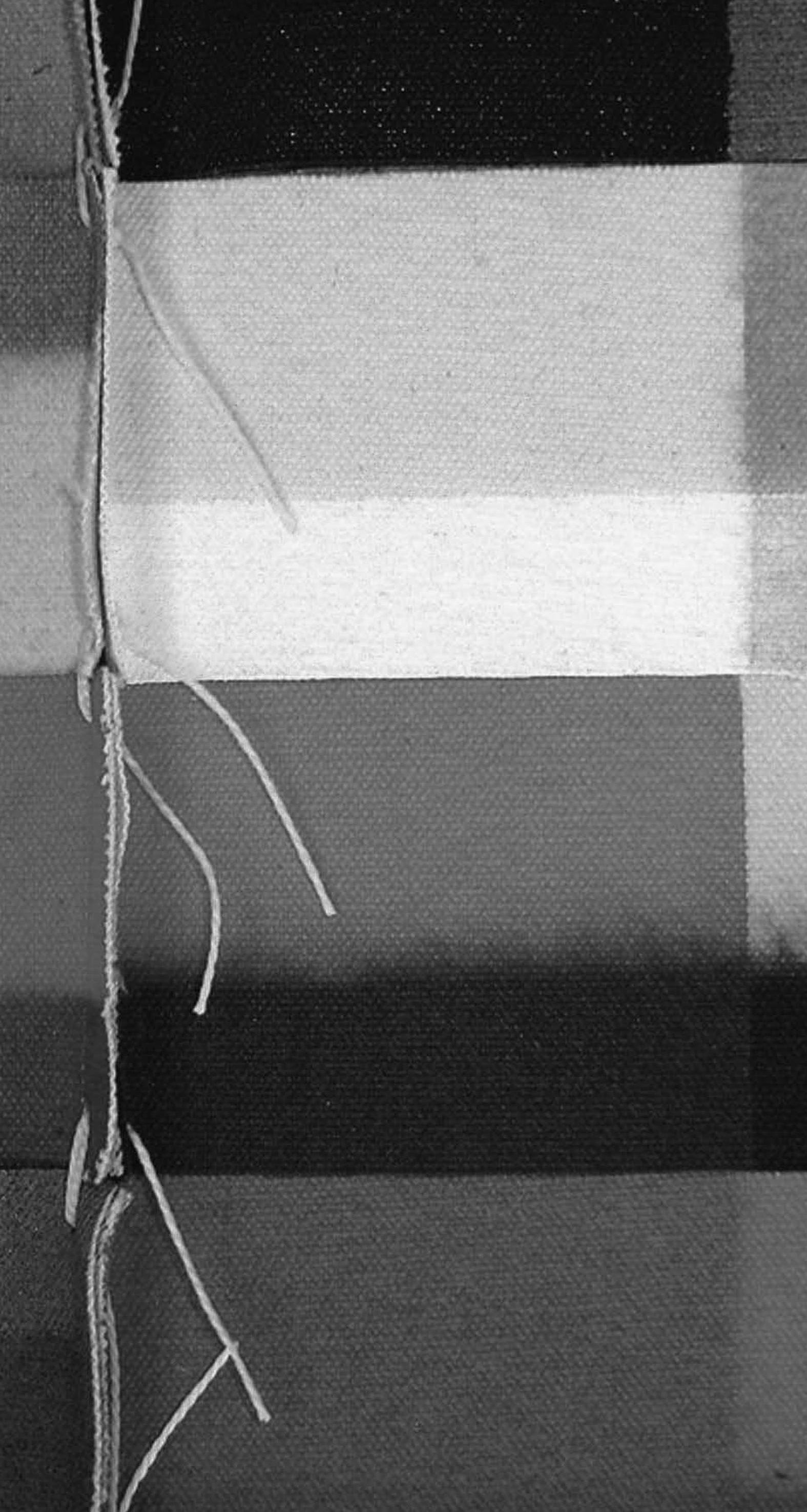




\section{O terno de anarruga: um ícone do guarda-roupa masculino americano}

\section{The seersucker suit: \\ an icon of American man's wardrobe}

[resumo] Embora já exista há mais de um século como uma alternativa ao terno de lã nos dias mais quentes do verão, 0 terno de anarruga continua amplamente desconhecido no Brasil. 0 objetivo deste texto é retratar os principais momentos da história do terno de anarruga, desde sua origem entre os homens mais pobres do Sul dos Estados Unidos, até seu reconhecimento como um verdadeiro ícone do guarda-roupa masculino americano.

[abstract] The seersucker suit remains largely unknown in Brazil, although it has been worn for more than one century by now as an alternative to the wool suit during the Summer hottest days. The aim of this paper is to point out some landmarks in the history of the seersucker suit, from its origin amongst the poor male population in the Southern United States to its acceptance as an iconic item in the American man's wardrobe. 
Na biografia de Dom Pedro II, o historiador José Murilo de Carvalho relata como o imperador costumava suar em bicas enquanto redigia cartas no verão de 1879 (CARVALHO, 2007). É difícil dizer com precisão o que Dom Pedro vestia nessa época, mas, considerando que desde 1874 ele era cliente e patrono da Henry Poole, a mais antiga casa de alfaiataria masculina da renomada Savile Row, em Londres, é bem provável que o imperador estivesse trajando alguma roupa escura de lã (HOWARTH, 2003). Mas será que chefes de Estado, juristas, banqueiros e líderes de partidos políticos da época não podiam contar com nenhuma alternativa às roupas de lã durante os dias quentes do verão? Não se sabe ao certo se essa questão foi seriamente proposta em algum momento na corte de Dom Pedro, mas, poucos anos após sua morte, alguns homens no Sul dos Estados Unidos, em uma posição similar àquela do último imperador brasileiro, começaram a buscar uma alternativa às pesadas roupas de lã, sem abrir mão da elegância.

Desde o final do século XIX, exigia-se de autoridades políticas que elas se apresentassem ao presidente dos Estados Unidos usando uma casaca escura (frock coat), do tipo que Dom Pedro passara habitualmente a trajar a partir da década de 1870 (SCHWARCZ, 1998; BARMAN, 1999). Embora o verão de 1903 tenha sido especialmente quente no hemisfério norte, ao se dirigir a Theodore Roosevelt, então presidente dos Estados Unidos, Joseph Gurney Cannon - que tinha no governo uma posição hierarquicamente inferior apenas à do vice-presidente - decidiu vestir um "paletó de anarruga" (seersucker jacket), formando a parte superior de um fraque. Ao explicar a razão para a inesperada quebra do protocolo, a resposta de Cannon não poderia ter sido mais direta: o tempo estava "quente pra burro" (damn hot) (MORRIS, 2001, p. 260). Mas o que era exatamente essa peça do vestuário masculino com a qual Cannon ousara se apresentar ao presidente americano?

0 objetivo deste artigo é reconstruir os principais marcos na história do terno ${ }^{1}$ de anarruga, ou seersucker suit, como é conhecido em inglês, deixando de lado outras utilizações em anarruga, como, por exemplo, seu uso na confecção dos uniformes das enfermeiras americanas durante a Segunda Guerra. Pouco mais de um século desde que Cannon ousou trajar um paletó de anarruga diante de um chefe de Estado, é curioso que o terno de anarruga, que veio a se tornar um verdadeiro ícone do guarda-roupa masculino americano, ainda seja amplamente desconhecido no Brasil. Fora do ambiente climatizado do Congresso, dos tribunais e dos escritórios, o percalço pelo qual passava nosso último imperador, durante o verão na Quinta da Boa Vista, continua basicamente o mesmo para muitos políticos, juristas e todos que, por motivos profissionais ou por força da vaidade, optam por vestir um terno mesmo sob o sol dos trópicos. 
Anarruga (ou seersucker) é um tipo de tecido listrado e de textura ligeiramente ondulada, especialmente adequado aos dias mais quentes e úmidos do ano. A palavra seersucker tem origem persa e significa, literalmente, "leite e açúcar", provavelmente como uma referência à sucessão de listras lisas e ásperas que caracterizam sua superfície. Originalmente, a textura crispada do anarruga era obtida, na Índia do século XIX, pelo emprego de fios de algodão e de seda na confecção de um mesmo tecido (MONTGOMERY e EATON, 2007; VILLAROSA e ANGELI, 1999). Como os dois fios têm elasticidades diferentes, o resultado era um tecido de textura ondulosa. São justamente as ondulações sobre a superfície do anarruga que o tornam especialmente adequado para o verão, pois elas permitem maior circulação de ar entre o tecido e a pele, aliviando, assim, a sensação de calor e facilitando a transpiração. Os oficiais britânicos, durante o período colonial na Índia, passaram a empregar o anarruga indiano - composto de fios de algodão e de seda - em seus uniformes (SCHOEFFLER e GALE, 1973).

Por outro lado, o anarruga inteiramente de algodão é obtido pela utilização alternada, durante o processo de fabricação, de fios de algodão ora mais, ora menos tensionados. É essa versão, em que se usam apenas fios de algodão, que começou a ser utilizada em Nova Orleans, no Sul dos Estados Unidos, a partir do início do século $X X$, graças à iniciativa pioneira de Joseph Haspel e seu irmão. A empresa que fundaram é, ainda hoje, uma das mais renomadas na fabricação do anarruga. $A$ ideia dos irmãos Haspel era criar um terno mais adequado ao clima quente e úmido em que viviam, como uma alternativa ao terno de lã tradicional (LACHOFF e KAHN, 2005).

Apesar do gesto irreverente e ousado de Cannon, anteriormente à Primeira Guerra Mundial o terno de anarruga era usado basicamente pela população mais pobre do Sul dos Estados Unidos. No entanto, como ocorreu com a música, com a pintura e com diversas formas de expressões artísticas, a moda masculina foi marcada, no período subsequente ao pós-guerra, por uma reação à cultura e às convenções sociais até então predominantes (THIEL, 2004). Nessa época, estudantes americanos começaram a vestir ternos de anarruga tanto fora quanto dentro do campus das universidades - especialmente em Princeton (GAVENAS, 2008; SCHOEFFLER e GALE, 1973; BOYER, 1985). A utilização desses ternos entre jovens mais abastados causava inicialmente uma certa confusão, pois, como relata Damon Runyon, um colunista da época, alguns de seus amigos não compreendiam se ele aderira ao seersucker suit por conta de dificuldades financeiras ou se ele estava tentando introduzir uma nova moda (SCHOEFFLER e GALE, 1973).

No final dos anos 1930, o terno de anarruga foi gradualmente deixando de ser associado à cultura regional sulista, passando a ser igualmente aceito pelos compatriotas do norte, como registra a revista Life, em 1939. Na década de 1940, celebridades do cinema americano, de férias em balneários da Califórnia e Bahamas, também contribuíram para a consolidação do seersuckersuit como uma opção elegante e confortável nos dias mais quentes do ano (CONSTANTINO, 1997). Os que podiam, estendiam suas 
férias à Europa e se recolhiam em localidades exuberantes como a Riviera Francesa, Cannes, Monte Carlo e Nice, introduzindo assim, no Velho Continente, o conceito até então ainda pouco difundido de "moda de verão" (CHENOUNE, 1993).

Foi durante o período em que viveu nas Bahamas que o Duque de Windsor (1894-1972) - ícone de elegância masculina no século XX - incorporou o anarruga ao seu guarda-roupa. Em seu livro de memórias, ele recorda a predileção que passou a cultivar pelo seersucker suit durante o verão (WINDSOR, 1960). Há, inclusive, uma foto do Duque na Riviera Francesa em 1948, em que ele é visto trajando um terno de anarruga ao lado da Duquesa Wallis Simpson.

A essa altura, o terno de anarruga já tinha deixado para trás o estigma de roupa para trabalhadores pobres do Sul dos Estados Unidos, passando a evocar, então, no imaginário da época, uma aura de lazer em grande estilo. Diversos escritores das décadas de 1940 e 1950 souberam capturar as novas associações que a visão de um terno de anarruga despertava. Jack Kerouac, por exemplo, ao recordar seu primeiro contato com o também escritor William Burroughs, em 1944, escreve o seguinte: Burroughs "era alto e usava óculos, magro em um terno de anarruga, como se ele tivesse acabado de retornar de um vilarejo na África Equatorial onde teria se sentado ao entardecer com um Martini" (citado por MAHER, 2004, p. 122, tradução nossa). Saul Bellow, escritor americano e prêmio Nobel de literatura publicou, em 1947, um romance intitulado $A$ vítima (The victim), no qual descreve: "Ele próprio estava usando um terno de anarruga que tinha acabado de voltar da lavanderia; e isso o fazia se sentir como pronto para as férias" (BELLOW, 1966, p. 89, tradução nossa).

Ao final da década de 1940, o terno de anarruga também foi gradualmente se misturando à paisagem mais urbana das grandes cidades, passando a ser usado, inclusive, em algumas ocasiões de maior formalidade. A revista Life, por exemplo, em uma reportagem publicada no verão de 1949, descreve como um jovem recém-egresso da universidade procurava se vestir alinhadamente, com um seersucker suit e gravata listrada, para disputar uma vaga no competitivo mercado de trabalho de Nova York naquela época.

Na década de 1950, o terno de anarruga já era tão popular nos Estados Unidos que se comentava na época: se o exército americano tivesse de convocar toda a população adulta masculina, não seriam necessários uniformes - bastaria que os homens se apresentassem em seus próprios ternos de anarruga (VILLAROSA e ANGELI, 1999). Para se ter uma ideia da popularidade que o terno de anarruga então desfrutava, no romance As ilhas das correntes (Islands in the stream), escrito no início dos anos 1950, mas publicado postumamente apenas em 1970, o escritor Ernest Hemingway narra como agentes do FBI costumavam vestir os tradicionais seersucker suits para poderem circular incógnitos entre os homens comuns da população.

No meio musical, o anarruga também encontrou alguns adeptos famosos. Em 1955, o trompetista Miles Davis lançou um álbum chamado The musings of Miles, cuja capa o mostra 
vestindo um paletó de anarruga e boné, mas sem gravata ou camisa. No verão do mesmo ano, ele subiu ao palco do festival de jazz de Newport vestindo, novamente, um paletó de anarruga, mas dessa vez, com uma gravata borboleta preta. 0 sucesso foi tanto que o paletó de anarruga, sem a calça formando um terno, acabou se tornando moda entre músicos de jazz (CROUCH, 2007; SZWED, 2004). Em sua edição de abril de 1961, a revista Esquire elegeu Miles Davis o homem mais elegante do mês. Talvez, por essa razão, no mesmo ano, ao se apresentar no Randall's Island Jazz Festival, a imprensa tenha feito uma cobertura minuciosa do seu guarda-roupa, referindo-se, por exemplo, ao terno de anarruga na cor rosa em que o trompetista descansaria após as apresentações (SZWED, 2004).

Em 1962, o seersucker suit foi parar nas telas de cinema, tornando-se coestrela do filme 0 sol é para todos (To kill a mockingbird), de 1962, no qual Gregory Peck, vestindo um terno de anarruga com colete, interpreta um advogado do Sul dos Estados Unidos disposto a lutar contra a segregação racial que imperava na década de 1920 . No entanto, a partir de meados dos anos 1960, com o advento do ar condicionado, o uso do terno de anarruga durante os dias mais quentes do ano foi gradativamente caindo em declínio, pelo menos entre os homens que tinham de passar o dia em prédios ou escritórios pouco ventilados.

Por outro lado, na mesma época, a indústria têxtil americana já começava a introduzir fibras sintéticas na composição do anarruga, de modo a the conferir uma aparência um pouco menos enrugada e, portanto, mais adequada ao ambiente corporativo das grandes empresas. Em sua edição de julho de 1960, a revista Playboy publicou um artigo inteiramente dedicado à "revitalização" do anarruga graças ao uso de fibras que amassavam menos (GREEN, 1960). Ainda assim, nas décadas subsequentes, o terno de anarruga esteve um pouco menos em voga, possivelmente devido à proliferação do uso de fibras sintéticas para atender à demanda por ternos mais leves e com menos propensão a se amarrotarem facilmente.

0 autêntico terno de anarruga, no entanto, jamais perdeu a aura de ícone do guarda-roupa masculino americano. ${ }^{2}$ Pelo contrário, os últimos anos têm presenciado na verdade um retorno do seersucker suit, até mesmo no ambiente formal do Congresso americano. Em 1996, o Senado americano instituiu o Seersucker Day, que ocorre sempre na segunda ou terceira quinta-feira de junho. Nesse dia, que coincide com o início do verão no hemisfério norte, muitos congressistas - não por coincidência, em sua maioria do Sul do país - tradicionalmente vestem o terno de anarruga. E, em 2006, o ex-presidente americano George Bush foi fotografado ao lado de seu filho, então presidente, vestindo um terno de anarruga durante uma cerimônia de casamento. Mas não é apenas o mundo da política que tem um Seersucker Day. Desde abril de 2008 o St. Jude Classic, tradicional campeonato de golfe nos Estados Unidos, também conta com um domingo dedicado ao famoso tecido - o Seersucker Sunday. No último dia do torneio, o vencedor, além da taça e do prêmio em dinheiro, ganha ainda um paletó de anarruga confeccionado pela legendária casa Brook Brothers, a mais antiga empresa de roupas clássicas masculinas nos Estados Unidos. 
É importante lembrar que a superfície ondulosa do terno de anarruga lhe confere um aspecto crispado, como se estivesse permanentemente amassado. ${ }^{3}$ Por essa razão, ainda hoje o terno de anarruga é visto por muitos homens com certa reserva, como se ele pudesse evocar uma impressão de desleixo com a própria aparência, um preconceito equivocado, pois esse terno é bem mais adequado ao nosso clima do que os tecidos de fibras sintéticas que entram na composição de boa parte dos ternos que circulam em nosso país. No entanto, uma desvantagem do terno de anarruga é que ele, por ser de algodão, costuma ter uma vida útil inferior a dos ternos de lã. ${ }^{4}$

\section{NOTAS}

${ }^{11]}$ A palavra "terno" será empregada aqui como referência não apenas à tradicional combinação de calça, colete, e paletó, de um mesmo tipo de tecido e padronagem, mas também à mesma combinação sem o colete, que se tornou mais usual na atualidade.

${ }^{[2]}$ A padronagem mais comum no terno de anarruga tradicional são listras brancas contrastando com listras nas cores azul claro, cinza ou bege, que podem variar em largura.

${ }^{[3]} 0$ efeito corrugado também é obtido por meio de um tratamento químico pelo qual alguns fios do tecido são preencolhidos (CAPELLEN, 2006: CHATAIGNIER, 2006). Dessa forma, economiza-se na produção, em detrimento, porém, da qualidade, pois, quando esticado, percebe-se facilmente que o tecido tratado quimicamente tem, na verdade, uma estrutura convencional. A produção do autêntico anarruga utilizado na confecção do clássico seersucker suit - consome mais tempo do que a produção do anarruga obtido pelo tratamento químico de um tecido convencional. Diferentemente deste, o verdadeiro anarruga é obtido mediante uma sucessão de listras verticais (formadas pelo urdume), submetidas a tensões diferentes. Isto é, no momento da tecelagem, os fios que formam uma listra são mais frouxos do que os fios da listra seguinte, submetidos a maior tensão. Após a conclusão da tecelagem, estes fios tendem a voltar ao seu comprimento normal, formando, então, as ondulações características do anarruga. Esse processo de tecelagem é mais trabalhoso e lento, tornando o anarruga autêntico mais caro do que 0 similar tratado quimicamente.

${ }^{[4]}$ As imagens que ilustram este artigo estão disponiveis em: <http://s1026.photobucket.com/albums/ y325/terno-de-anarruga>. 


\section{REFERÊNCIAS}

A 1949 college graduate pounds pavements, but jobs are scarce. Life. Nova York, Time, v. 27, n 1, p. 16, 4 jul. 1949.

BARMAN, Roderick. Citizen Emperor: Pedro II and the making of Brazil, 1825-1891. Chicago: Standford University Press, 1999.

BELLOW, Saul. The victim. Londres: Penguin Books, 1966.

BOYER, Bruce G. Elegance: a guide to quality in menswear. Nova York: W. W. \& Company, 1985.

CAPELLEN, Thomas Meyer zur. Seersucker. In: . Lexikon der gewebe. Frankfurt: Deutscher Fachverlag, 2006.

CARVALHO, José Murilo. D. Pedro II. São Paulo: Companhia das Letras, 2007.

CHATAIGNIER, Gilda. Fio a fio: tecidos, moda e linguagem. São Paulo: Estação das Letras, 2006.

CHENOUNE, Farid. A history of men's fashion. Paris: Flammarion, 1993.

CONSTANTINO, Maria. Men's fashion in the twentieth century: from frock coats to intelligent fibres. Londres: Batsford Books, 1997.

CROUCH, Stanley. Considering genius: writings on jazz. Nova York: Basic Civitas Books, 2007.

GAVENAS, Mary Lisa. The Fairchild encyclopedia of menswear. Nova York: Fairchild Publications, 2008.

GREEN, Robert L. Seersucker circa 60. Playboy, Chicago, Playboy Enterprises, p. 37, jul. 1960.

HEMINWAY, Ernest. Islands in the stream. Nova York: Simon \& Schuster, 1970.

HOWARTH, Stephen. Henry Poole: founders of Savile Row: the making of a legend. Londres: Bene Factum Publishing, 2003.

LACHOFF, Irwin; KAHN, Catherine C. The jewish community of New Orleans. Mount Pleasant: Arcadia Publishing, 2005.

MAHER, Paul. Kerouac: the definitive biography. Lanham: Taylor Trade Publishing, 2004.

MONTGOMERY, Florence M.; EATON, Linda. Textiles in America: 1650-1870. Nova York: W. W. Norton \& Company, 2007.

MORRIS, Edmund. Theodore Rex. Nova York: Random House, 2001.

NORTHERNERS succumb to summer suits. Life, Nova York, Time, v. 7, n 3, p. 40-43, 17 jul. 1939.

SCHOEFFLER, O. E.; GALE, William: Esquire's encyclopedia of 20th men's fashions. Nova York: McGrawllhill, 1973.

SCHWARCZ, Lilia Moritz. As barbas do imperador: D. Pedro II, um monarca nos trópicos. São Paulo: Companhia das Letras, 1998

SZWED, John. So what: the life of Miles Davis. Nova York: Simon \& Schuster, 2004.

THIEL, Érika. Geschichte des kostüms: die europäische mode von den anfängen bis zur gegenwart. Berlim: Henschel, 2004.

VILLAROSA, Riccardo; ANGELI, Giuliano. The elegant man: how to construct the ideal wardrobe. Nova York: Random House, 1999.

WINDSOR, Edward Duke of. Windsor revisited. Boston: Houghton Mifflin, 1960. 